\title{
BMJ
}

\section{Postoperative pneumonia in elderly patients receiving acid suppressants: a retrospective cohort analysis}

\author{
Donald A Redelmeier, professor of medicine, ${ }^{1,2,3,4}$ Finlay A McAlister, professor, ${ }^{5}$ Christopher E Kandel, \\ medical student, ${ }^{1}$ Hong Lu, statistical analyst, ${ }^{3}$ Nick Daneman, assistant professor ${ }^{1,2,3}$
}

${ }^{1}$ Department of Medicine, University of Toronto, Toronto, Canada

${ }^{2}$ Clinical Epidemiology Program, Sunnybrook Health Sciences Centre, Ontario, Canada

${ }^{3}$ Institute for Clinical Evaluative Sciences in Ontario, Ontario,

Canada

${ }^{4}$ Patient Safety Service,

Sunnybrook Health Sciences

Centre

${ }^{5}$ Department of Medicine, University of Alberta, Edmonton,

Canada

Correspondence to: D

A Redelmeier, Sunnybrook Health

Sciences Centre, G-151, 2075

Bayview Ave, Ontario, Canada M4N

3M5 dar@ices.on.ca

Cite this as: $B M J$ 2010;340:c2608 doi:10.1136/bmj.c2608

\section{ABSTRACT}

Objective To test whether gastric acid suppressants are associated with an increased risk of postoperative pneumonia in patients undergoing elective surgery. Design Population-wide retrospective cohort analysis. Setting Canadian acute care hospitals between 1 April 1992 and 31 March 2008.

Patients Consecutive patients aged $>65$ years admitted for an elective operation.

Outcome measure Postoperative pneumonia recorded in inpatient postoperative notes.

Results A total of 593265 patients were included, of whom about $21 \%$ were taking an acid suppressant (most commonly omeprazole or ranitidine). Overall, 6389 patients developed postoperative pneumonia, with a rate significantly higher for those taking acid suppressants (13 per 1000) than controls (10 per 1000), equivalent to a $30 \%$ increase in frequency (odds ratio 1.30 (95\% confidence interval 1.23 to 1.38 ), P $\mathrm{P} 0.001$ ). However, no increase in risk was observed after adjustment for duration of surgery, site of surgery, and other confounders (odds ratio 1.02 (0.96 to 1.09), $\mathrm{P}=0.48$ ). The general safety of acid suppressants extended to those patients prescribed proton pump inhibitors, experiencing long term treatment, receiving high doses, and undergoing high risk procedures.

Conclusion After adjustment for patient and surgical characteristics, acid suppressants are not associated with an increased risk of postoperative pneumonia among elderly patients admitted for elective surgery.

\section{INTRODUCTION}

Pneumonia is a common, serious, and potentially lethal complication following elective surgery. The incidence varies between $2 \%$ and $20 \%$ (depending on the patient population and the strategy used to diagnose pneumonia), is more common than cardiac complications in most settings, and collectively affects about a million surgical patients each year in North America. ${ }^{12}$ Multiple clinical prediction rules have consistently identified several risk factors including patient age, duration of surgery, and site of surgery. ${ }^{3}$ Overall, the case fatality rate is about $10 \%$ and the mean attributable increased length of hospital stay is about eight days. ${ }^{4}$
Gastric acid suppressants have become a focus of concern given their trade-off between reducing acid related upper gastrointestinal diseases yet inducing bacterial overgrowth of the stomach and oesophagus, ${ }^{56}$ and therefore raising the risk of aspiration pneumonia. ${ }^{7}$ Two large randomised trials in intensive care units observed that gastric acid suppressants led to a twofold to threefold increase in the incidence of ventilator associated pneumonia. ${ }^{89}$ In contrast, recent analyses of outpatients yielded conflicting results about a potential increase in the incidence of community acquired pneumonia. ${ }^{10-15}$ No large study has compared rates of postoperative pneumonia in patients receiving chronic gastric acid suppressants and in those not taking such medications. ${ }^{16}$

Published guidelines have called for more research on such potential risks since gastric acid suppressants are among the world's most commonly used medications and are sometimes available without prescription. ${ }^{17-19}$ The purpose of this study was to test whether acid suppressants are associated with an increased risk of postoperative pneumonia. We examined acid suppressants as an entire group as well as distinguished by class (proton pump inhibitors, $\mathrm{H}_{2}$ antihistamines, and miscellaneous agents). We focused on older patients because this group accounts for most major operative procedures, cases of postoperative pneumonia, and surgical deaths.

\section{METHODS}

Patient selection

We identified consecutive patients older than 65 years admitted for elective surgery in all Ontario hospitals between 1 April 1992 and 31 March 2008 through the Canadian Institutes for Health Information databases. These databases have been validated previously, and we used all 16 years available for analysis. ${ }^{20-22}$ We did not include outpatients, those who had day surgery, or younger patients because of the low rate of pneumonia in these groups and the lack of available prescribing data. Patients who underwent multiple procedures were analysed according to first presentation so that each patient counted only once in each analysis. Our focus was on elective operations to ensure a cohort free of active pneumonia at the time 
of inception. The study design was approved by the Sunnybrook Research Ethics Committee.

\section{Acid suppressants}

For each patient, we searched prescription records from the universal drug database for the year before admission, reasoning that these drugs would customarily be continued perioperatively. This assumption is in line with standard practices that recommend continuing acid suppressants (for those already receiving them) but not initiating acid suppressants prophylactically (for those not already receiving them). ${ }^{23}$ We classified patients who received two or more prescriptions for an acid suppressant in the year before surgery (including at least one prescription in the 90 days before surgery) as receiving this drug on a chronic basis. Otherwise, we classified the patient as a control. This strategy assured that ascertainment was blinded, free of reverse causality bias, conservative in design, and congruent with prior research. ${ }^{24}$

\section{Specific medications}

We distinguished prescriptions according to drug, dose, and duration. The specific drugs were lansoprazole, omeprazole, pantoprazole, rabeprazole (proton pump inhibitors); cimetidine, famotidine, nizatidine, ranitidine $\left(\mathrm{H}_{2}\right.$ antihistamines); and aluminium hydroxide, misoprostol, and sucralfate (miscellaneous group). The dose was classified by separating those prescribed the median amount or less of each drug (such as omeprazole $20 \mathrm{mg}$ ) from those prescribed higher doses (such as omeprazole $40 \mathrm{mg}$ ). The duration of therapy was calculated from the date of the initial prescription and allowing up to a 120 day supply (based on prescribing practices in this region and uncertain patient adherence). ${ }^{25}$ These methods were similar to those in recent studies linking acid suppressants to community acquired pneumonia.

Validating medications-Acid suppressants were generally available only by prescription in Canada during the study interval (oral antacids being the main exception). A prior validation study indicated that the prescription drug database has an accuracy rate of $99 \%$ when compared with pharmacy records. ${ }^{26}$ Additionally, we tested for misclassification by using more expansive and restrictive definitions of medication exposure. The expansive definition included patients who had any prescription for an acid suppressant in the year before surgery. The restricted definition required four or more prescriptions for an acid suppressant in the year before surgery (with at least one in the 90 days before surgery). We also developed a "clearest case" analysis by analysing patients who stayed consistent with both expansive and restrictive definitions of medication use.

\section{Pneumonia outcomes}

The primary outcome was the development of pneumonia during a patient's hospital stay based on the full inpatient record and coded according to the international classification of diseases (ICD-9 codes 480.0 to 487.9 for years 1992 to 2002 , and ICD-10 codes J10.0 to J18.9 for years 2002 to 2008). Surgical complications such as pneumonia are not always identified by clinicians, rigorously recorded in a patient's chart, or entered into databases. Hence, the codes are specific (about 98\%) but not sensitive (about 35\%). ${ }^{27-30}$ We also conducted alternative analyses with wider and narrower codes for pneumonia. To validate our results and examine the more severe spectrum, we also considered complex combinations of outcomes-namely, patients who experienced postoperative pneumonia and had a prolonged stay in hospital ( $\geq 7$ days), required admission to an intensive care unit, or died in hospital after surgery.

\section{Risk factors}

We measured the major predictors of postoperative pneumonia established in systematic reviewsnamely, patient age, chronic obstructive lung disease, surgical site, duration of anaesthesia, ASA (American Society of Anesthesia) score, and use of a nasogastric tube. We estimated the duration of surgery from anaesthesia billing logs reported in 15 minute intervals using methods validated elsewhere. ${ }^{31}$ Estimates of ASA scores that classify patients before surgery reflected anaesthesia billing and diagnoses in the year before surgery in accord with past research. ${ }^{32}$ Use of a nasogastric tube was based on physician fee codes (G322, G355, G356, G357). The available databases did not contain reliable information on obesity, spirometry, radiology, current smoking status, or functional dependence.

Additional risk factors-We also gathered data on other factors associated with postoperative pneumonia in some studies. ${ }^{334}$ We derived the patients' age, sex, and income quintile from the Ontario Registered Persons Database. ${ }^{35}$ We identified drug therapy for lung disease at baseline by assessing prescriptions for an inhaled bronchodilator in the year before admission. We determined the use of other chronic treatments by searching for prescriptions for systemic corticosteroids, benzodiazepines, opioid analgesics, antipsychotics, antidepressants, and gastric motility agents in accord with prior research. ${ }^{36}$ Comorbidities were based on the Charlson index. ${ }^{37}$ Global counts of prior outpatient and inpatient care were based on measures under universal insurance. ${ }^{38}$ We did not account for geographical location or characteristics of the hospital.

\section{Statistical analysis}

For the crude comparison, we used the $\chi^{2}$ test to compare the frequency of postoperative pneumonia in those patients taking acid suppressants with those who were not taking acid suppressants. In the primary analysis we used multivariable logistic regression to adjust this comparison for patient and procedure factors, since the time of onset of pneumonia was not recorded. Propensity score matched analyses yielded nearly identical results to regression analysis and are not reported. We tested for selection bias through a secondary analysis of patients who had received an 
Table 1 |Characteristics of patients aged $>65$ years admitted for elective surgery categorised by treatment with gastric acid suppressants (cases). Values are percentages unless specified otherwise

\begin{tabular}{|c|c|c|}
\hline Characteristic & $\begin{array}{c}\text { Cases } \\
(n=121850)\end{array}$ & $\begin{array}{c}\text { Controls } \\
(n=471415)\end{array}$ \\
\hline Mean (SD) age (years) & $74.7(6.1)$ & $74.0(6.0)$ \\
\hline Female & 55.0 & 47.4 \\
\hline \multicolumn{3}{|l|}{ Social status*: } \\
\hline Lower & 62.8 & 59.6 \\
\hline Higher & 35.8 & 39.3 \\
\hline Missing & 1.4 & 1.1 \\
\hline \multicolumn{3}{|l|}{ Past diagnoses: } \\
\hline COPD & 27.8 & 20.2 \\
\hline Asthma & 12.6 & 8.6 \\
\hline Heart failure & 14.9 & 9.9 \\
\hline Parkinson's disease & 1.7 & 1.4 \\
\hline Pneumonia & 13.1 & 9.0 \\
\hline Stroke & 12.8 & 10.2 \\
\hline \multicolumn{3}{|l|}{ Chronic treatments: } \\
\hline Systemic corticosteroid & 5.3 & 2.1 \\
\hline Inhaled $\beta$ agonist & 8.2 & 4.4 \\
\hline Inhaled anticholinergic & 4.1 & 2.1 \\
\hline Inhaled corticosteroid & 8.5 & 4.6 \\
\hline Opioid analgesic & 21.9 & 11.5 \\
\hline Benzodiazepine & 25.8 & 13.2 \\
\hline Antipsychotic & 2.2 & 1.4 \\
\hline Antidepressant & 12.3 & 5.8 \\
\hline Gastric motility agent & 8.2 & 1.2 \\
\hline \multicolumn{3}{|c|}{ Mean (SD) No of hospital visits in past 3 years: } \\
\hline Outpatient visits & $49.3(33.4)$ & $38.0(26.7)$ \\
\hline Inpatient admissions & $1.0(2.1)$ & $0.6(1.3)$ \\
\hline Mean (SD) Charlson score & $0.7(1.4)$ & $0.6(1.4)$ \\
\hline \multicolumn{3}{|l|}{ Type of surgery: } \\
\hline Cardiac & 9.7 & 9.2 \\
\hline Thoracic & 2.6 & 2.5 \\
\hline Neurosurgical & 1.8 & 1.6 \\
\hline Vascular & 5.9 & 6.2 \\
\hline Musculoskeletal & 22.7 & 19.1 \\
\hline Abdominal & 26.0 & 23.8 \\
\hline Retroperitoneal & 1.2 & 1.4 \\
\hline Lower urogenital & 17.6 & 22.8 \\
\hline Breast and skin & 4.7 & 5.5 \\
\hline External head and neck & 2.8 & 3.3 \\
\hline Ophthalmological & 4.7 & 4.4 \\
\hline Unclassified & 0.3 & 0.3 \\
\hline \multicolumn{3}{|l|}{ Postoperative care†: } \\
\hline Nasogastric tube & 3.1 & 2.6 \\
\hline Hypoalbuminaemia & 0.2 & 0.1 \\
\hline Mean (SD) ASA score & $2.0(0.7)$ & $1.9(0.7)$ \\
\hline Mean (SD) duration of surgery (hours) & $2.2(1.5)$ & $2.2(1.5)$ \\
\hline
\end{tabular}

$\mathrm{COPD}=$ chronic obstructive pulmonary disease.

*Based on income quintile derived from the Ontario Registered Persons Database, dichotomised as the three lowest fifths and the two highest fifths.

†Derived from Ontario Health Insurance (OHIP) billing codes: codes G322, G355, G356, G357 for nasogastric tube; code 263 for hypoalbuminaemia.

fASA (American Society of Anesthesia) score ranges from 1 to 5, higher values indicating sicker patients. acid suppressant in the past year but not in the 90 days before surgery. We tested further for hidden confounders in stratified analyses accounting for duration of use, specific medication, and relative dose.

\section{RESULTS}

During the 16 year interval a total of 955914 elective operations were conducted on 593265 patients involving 269 hospitals and 4195 surgeons. We observed no major trends over the years. The typical patient was 74 years old; underwent an abdominal, musculoskeletal, or lower urogenital operation; and had an average duration of anaesthesia of 132 minutes. Neurosurgical and retroperitoneal operations were the least common surgeries, yet still amounted to thousands of patients (9754 and 7911, respectively). The median length of stay was four days, about a quarter of patients $(\mathrm{n}=152$ 998) stayed in hospital more than a week, and $13 \%(n=74222)$ were admitted to a critical care unit. Relatively few patients were hospitalised for pneumonia during the year before surgery $(\mathrm{n}=4812)$.

About $21 \%$ of patients $(n=121850)$ were taking an acid suppressant, and 79\% ( $\mathrm{n}=471415)$ were not taking an acid suppressant before surgery. The two groups were similar in mean age, duration of surgery, and ASA scores (table 1). Multiple other risk factors for postoperative pneumonia were imbalanced against the acid suppressant group, including a history of chronic lung disease and prior pneumonia. Acute gastrointestinal bleeding was rarely diagnosed in the postoperative setting $(\mathrm{n}=226)$, particularly among patients receiving acid suppressants (odds ratio 0.73 (95\% confidence interval 0.51 to 1.05$)$ ). The most commonly used acid suppressants were omeprazole $(n=25948)$ and ranitidine $(n=45531)$, and most patients $(74 \%)$ had received treatment for several years before surgery.

Postoperative pneumonia was diagnosed in 6389 patients after surgery (roughly 11 per 1000). The frequency of this outcome was about a third higher among patients taking acid suppressants before surgery (13 per 1000) than among controls (10 per 1000) (odds ratio 1.30 (1.23 to 1.38 ), $\mathrm{P}<0.001)$. Accounting for age, sex, type of surgery, and duration of anaesthesia yielded a smaller increase in risk (odds ratio 1.20 (1.13 to 1.28)). Accounting for chronic lung disease, prior pneumonia, and hypoalbuminaemia yielded further attenuation (odds ratio 1.12 (1.05 to 1.19)). The final multivariable model, which adjusted for all baseline characteristics, showed no significant increase in the risk of postoperative pneumonia associated with acid suppressants (adjusted odds ratio 1.02 (0.96 to 1.09)).

The apparent safety of acid suppressants was evident across a variety of patient and procedure factors. Each analysis yielded no major increase in the risk of postoperative pneumonia, although the confidence intervals were broad in a few subgroups (figure). Overall, 11 of the 29 prespecified subgroups indicated a point estimate below 1.00, and 27 of the 29 prespecified subgroups showed a nominal $\mathrm{P}$ value $>0.05$. The findings were highly consistent among patients with different 
ages, durations of surgery, and ASA scores, as well as those with a history of lung disease or prior pneumonia. All of the prespecified subgroups overlapped the 95\% confidence interval of the main analysis, as did a post hoc subgroup analysis restricted to patients undergoing thoracic surgery (odds ratio 1.06 (0.88 to 1. 28)).

Our findings were consistent across different drug classes and doses of acid suppressants. Proton pump inhibitors (the most potent acid suppressants) were

\begin{tabular}{|c|c|c|c|c|}
\hline Subgroup & $\begin{array}{c}\text { No of } \\
\text { events }\end{array}$ & $\begin{array}{c}\text { Sample } \\
\text { size }\end{array}$ & $\begin{array}{c}\text { Odds ratio } \\
\text { (95\% Cl) }\end{array}$ & \\
\hline Total cohort & 6389 & 593265 & & \\
\hline \multicolumn{5}{|l|}{ Age (years) } \\
\hline$<75$ & 3171 & 342561 & -7 & \\
\hline$\geq 75$ & 3218 & 250704 & & \\
\hline Female & 2532 & 190416 & $\rightarrow$ & \\
\hline Male & 3857 & 302849 & & \\
\hline \multicolumn{5}{|l|}{ Social status } \\
\hline Lower & 4040 & 229045 & & \\
\hline Higher & 2295 & 357473 & & \\
\hline \multicolumn{5}{|l|}{ Past diagnoses } \\
\hline COPD & 2467 & 129118 & & \\
\hline Asthma & 828 & 55924 & & \\
\hline Heart failure & 1303 & 64733 & $\rightarrow$ & \\
\hline Parkinson's disease & 140 & 8888 & - & \\
\hline Pneumonia & 1500 & 58448 & & \\
\hline Stroke & 948 & 63602 & $\rightarrow-$ & \\
\hline \multicolumn{5}{|c|}{ No of clinic visits in past 3 years } \\
\hline$\ll 30$ & 2035 & 243273 & $\rightarrow$ & \\
\hline$\geq 30$ & 4354 & 349992 & $\vdash$ & \\
\hline \multicolumn{5}{|c|}{ No of hospitalisations in past 3 years } \\
\hline 0 & 2932 & 364231 & & \\
\hline$\geq 1$ & 3457 & 229034 & & \\
\hline \multicolumn{5}{|l|}{ Charlson score } \\
\hline 0 & 2545 & 430723 & & \\
\hline 1 & 1648 & 91377 & $\rightarrow$ & \\
\hline$\geq 2$ & 2196 & 71165 & $\rightarrow-$ & \\
\hline \multicolumn{5}{|l|}{ Type of surgery } \\
\hline Cardiac & 1077 & 55225 & & \\
\hline \multicolumn{5}{|l|}{ Non-cardiac } \\
\hline High risk & 2608 & 178496 & $\rightarrow$ & \\
\hline Medium risk & 1919 & 153169 & 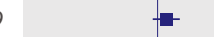 & \\
\hline Low risk & 785 & 206375 & $\rightarrow-$ & \\
\hline \multicolumn{5}{|l|}{ ASA score } \\
\hline 1 & 794 & 164545 & 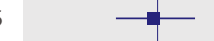 & \\
\hline 2 & 3998 & 343417 & - & \\
\hline$\geq 3$ & 1597 & 85303 & $\rightarrow$ & \\
\hline \multicolumn{5}{|c|}{ Duration of surgery (hours) } \\
\hline$<3$ & 2407 & 411525 & - & \\
\hline \multirow[t]{3}{*}{$\geq 3$} & 3096 & 123477 & - & \\
\hline & & & 0.5 & 2 \\
\hline & & & $\begin{array}{l}\text { Decreased } \\
\text { risk }\end{array}$ & $\begin{array}{l}\text { ased } \\
\text { risk }\end{array}$ \\
\hline
\end{tabular}

Association of postoperative pneumonia with taking acid suppressants in patients aged $>65$ years admitted for elective surgery, analyses for total cohort and subgroups. Odds ratios from adjusted multivariable analysis using logarithmic scale: result for total cohort is $1.02(95 \% \mathrm{Cl} 0.96$ to 1.09$)$. $(\mathrm{COPD}=$ chronic obstructive pulmonary disease, $\mathrm{ASA}=\mathrm{American}$ Society of Anesthesia) associated with no significant risk of postoperative pneumonia (adjusted odds ratio 0.97 (0.88 to 1.06)). Similarly, $\mathrm{H}_{2}$ antihistamines also appeared safe (adjusted odds ratio 1.07 (0.98 to 1.17)), as did miscellaneous acid suppressants (adjusted odds ratio 1.13 (0.93 to 1.37)). Patients prescribed doses at or below the median showed no increase in the risk of postoperative pneumonia (adjusted odds ratio 1.03 (0.94 to 1.13)), nor did patients prescribed higher doses (adjusted odds ratio 1.01 (0.93 to 1.10)).

We found no major anomalies related to duration of treatment. Patients treated for multiple years showed no significant increase in risk (adjusted odds ratio 1.01 (0.93 to 1.08)). Similarly, patients treated for a single year showed no significant increase (adjusted odds ratio 1.07 (0.96 to 1.19$)$ ). Patients ( $\mathrm{n}=79517)$ who were former users and had received an acid suppressant in the past (but none within the 90 days before surgery) showed no significant increase or decrease (adjusted odds ratio 1.01 (0.93 to 1.10)). Patients $(\mathrm{n}=28975)$ who started an acid suppressant acutely before surgery (one prescription within 30 days of surgery and none earlier) showed no significant increase in risk (adjusted odds ratio 1.08 (0.97 to 1.20$)$ ).

We explored whether pneumonia was any more severe for patients receiving acid suppressants compared with those patients not receiving acid suppressants. For example, patients who developed pneumonia were about four times more likely than those who did not develop pneumonia to be admitted to an intensive care unit after surgery $(54 \% v 12 \%, \mathrm{P}<0.001)$. Similarly, patients who developed pneumonia were more likely than patients who did not develop pneumonia to stay in hospital more than a week $(89 \% v 32 \%$, $\mathrm{P}<0.001)$ or die during hospitalisation $(18 \%$ v $1 \%$, $\mathrm{P}<0.001)$. Acid suppressants were not associated with a significant increase in any of these severe forms of pneumonia (table 2). Overall, we observed a 12 day absolute increase in median length of stay for all patients who developed postoperative pneumonia (16 days $v 4$ days, $\mathrm{P}<0.001$ ) and no differential increase for those receiving acid suppressants compared with controls.

As expected, other factors were significant predictors of postoperative pneumonia. The type of surgery was extremely important (table 3), with the highest risks observed for thoracic procedures and lowest risks for ophthalmological procedures. Duration of surgery was also important, equivalent to about a 1\% relative increase in risk for each 2 minutes of time. Age, sex, insertion of a nasogastric tube, postoperative hypoalbuminaemia, and various comorbidities were each independent predictors (in accord with past research). The overall predictive accuracy of the 10 factors was strong (C statistic 0.81 ). All other baseline characteristics (listed in table 1) were not associated with a significant independent increase in risk, including gastric motility agents (adjusted odds ratio 1.07 (0.92 to 1.25$))$. 
Table 2 |Association of pneumonia with taking gastric acid suppressants among patients aged $>65$ years admitted for elective surgery

\begin{tabular}{llcc} 
& $\begin{array}{c}\text { No of } \\
\text { events }\end{array}$ & $\begin{array}{c}\text { Sample } \\
\text { size }\end{array}$ & $\begin{array}{c}\text { Adjusted odds ratio } \\
\text { (95\% CI)* }\end{array}$ \\
\hline Main analysis & 6389 & 593265 & 1.02 (0.96 to 1.09) \\
\hline Any pneumonia & 1181 & 593265 & $0.95(0.81$ to 1.10) \\
\hline Pneumonia plus death & 3460 & 593265 & 1.05 (0.96 to 1.15) \\
\hline Pneumonia with admission to critical care unit & 5705 & 593265 & 1.03 (0.96 to 1.10) \\
\hline Pneumonia with prolonged hospital stayt & & &
\end{tabular}

Exposure to acid suppressantsł:

\begin{tabular}{lccc}
\hline Expanded definition & 6389 & 593265 & 1.02 (0.96 to 1.08) \\
\hline Restricted definition & 6389 & 593265 & 1.05 (0.97 to 1.13) \\
\hline Clearest case definition & 5129 & 486600 & 1.04 (0.96 to 1.12) \\
\hline Pneumonia outcome§: & & & \\
\hline Wide definition & 42719 & 593265 & 1.02 (0.99 to 1.05) \\
\hline Narrow definition & 4331 & 593265 & 1.04 (0.96 to 1.12) \\
\hline Clearest case definition & 4331 & 554877 & $1.03(0.95$ to 1.11) \\
\hline
\end{tabular}

*Results from fully adjusted multivariate analysis accounting for all baseline characteristics.

†Hospital stay $\geq 1$ week.

$\ddagger$ Definitions of exposure to acid suppressants: standard criteria $\geq 2$ scripts; expanded criteria $\geq 1$ script;

restricted criteria $\geq 4$ scripts; clearest case criteria, exposures defined by restricted criteria and non-exposures

by expanded criteria.

§Definitions of pneumonia: wide criteria, diagnostic codes ICD-9 480.0-508.9 and ICD-10 J10.0-J22.9, J40.0-

J70.9; narrow criteria, diagnostic codes ICD-9 481.0-486.9 and ICD-10 J13.0-J15.9; clearest case criteria, events defined by narrow criteria and non-events by wide criteria.

\section{DISCUSSION}

\section{Overview}

We studied elderly patients undergoing elective surgery over a 16 year interval. We found that pneumonia was a common complication, with more events in the few days after the operation than in the full year before the operation. The average case increased the length of hospital stay by more than 10 days and increased the patient's risk of death more than 10 -fold. We also found that the type of patient prone to receive a gastric acid suppressant was also the type of patient predisposed to pneumonia. After accounting for patient and surgical risk factors, we found the risk of postoperative pneumonia was no higher with an acid suppressant compared with no acid suppressant. The apparent safety of acid suppressants was particularly evident for patients treated for multiple years, receiving proton pump inhibitors, prescribed high doses, and undergoing high risk surgical procedures.

\section{Future research}

The upper bound of almost all observed confidence intervals suggests that our study excludes a clinically important increase in risk with acid suppressants (estimated 1000 patients needed to be treated to potentially add one postoperative pneumonia case). Trial data are unlikely to overturn this result given the difficulties of recruiting patients into randomised studies in surgery and the obstacles of funding research on generic drugs. Moreover, our data imply that other risk factors are a greater priority for targeting interventions to reduce postoperative pneumonia risk; in particular, duration of surgery, antipsychotic medications, nasogastric tubes, and postoperative hypoalbuminaemia.
Indirectly, our study also contrasts with recent research on the association between acid suppressants and pneumonia observed in non-surgical settings. ${ }^{39-41}$

\section{Main limitation}

The most important limitation of our study is that it is not a randomised trial that eliminates all confounding. However, the controlled nature of inpatient elective surgical services argues against major confounding from active smoking, ongoing alcohol consumption, reverse causality, or other confounders relevant to community acquired pneumonia. ${ }^{42}$ The analyses, in addition, provided data on almost all major clinical predictors, and the results (tables 2 and 3) yield a pattern that is difficult to attribute to misclassification of pneumonia outcomes or medication exposures. ${ }^{43}$ The main advantage of a randomised trial would be in prospective data collection to obtain more information about microbiology, radiology, medication compliance, clinical course, long term outcomes, milder

Table 3|Potential predictors of postoperative pneumonia among 593265 patients aged $>65$ years admitted for elective surgery

\begin{tabular}{|c|c|}
\hline Characteristic & $\begin{array}{l}\text { Adjusted odds ratio } \\
\qquad(95 \% \mathrm{Cl})^{\star}\end{array}$ \\
\hline Age, per decade increase & 1.54 (1.47 to 1.61$)$ \\
\hline Sex, men relative to women & $1.29(1.22$ to 1.37$)$ \\
\hline \multicolumn{2}{|l|}{ Past diagnoses: } \\
\hline COPD & 1.48 (1.38 to 1.59$)$ \\
\hline Asthma & $0.76(0.69$ to 0.83$)$ \\
\hline Heart failure & $1.25(1.16$ to 1.35$)$ \\
\hline Parkinson's disease & $1.36(1.12$ to 1.66$)$ \\
\hline Pneumonia & 1.67 (1.55 to 1.79$)$ \\
\hline \multicolumn{2}{|l|}{ Chronic treatments: } \\
\hline Systemic corticosteroid & $1.16(1.01$ to 1.33$)$ \\
\hline Inhaled $\beta$ agonist & $1.18(1.05$ to 1.33$)$ \\
\hline Inhaled anticholinergic & 1.21 (1.06 to 1.38$)$ \\
\hline Inhaled corticosteroid & 1.24 (1.11 to 1.38$)$ \\
\hline Benzodiazepine & 1.14 (1.06 to 1.30$)$ \\
\hline Antipsychotic & 1.61 (1.34 to 1.92$)$ \\
\hline Antidepressant & 1.18 (1.07 to 1.30$)$ \\
\hline Inpatient admissions, $\geq 1$ in past 3 years & $1.02(1.01$ to 1.03$)$ \\
\hline Charlson score, per unit increase & 1.18 (1.16 to 1.19$)$ \\
\hline \multicolumn{2}{|l|}{$\begin{array}{l}\text { Type of surgery, relative to abdominal } \\
\text { surgery: }\end{array}$} \\
\hline Cardiac & $1.26(1.14$ to 1.38$)$ \\
\hline Thoracic & $2.72(2.46$ to 3.00$)$ \\
\hline Vascular & $1.38(1.25$ to 1.52$)$ \\
\hline Musculoskeletal & 0.75 (0.69 to 0.82$)$ \\
\hline Lower urogenital & $0.30(0.26$ to 0.34$)$ \\
\hline Breast and skin & 0.21 (0.16 to 0.28$)$ \\
\hline Ophthalmological & 0.07 (0.04 to 0.12$)$ \\
\hline \multicolumn{2}{|l|}{ Postoperative care: } \\
\hline Nasogastric tube present & 1.24 (1.12 to 1.38$)$ \\
\hline Hypoalbuminaemia present & $5.74(4.64$ to 7.10$)$ \\
\hline Duration of surgery, per 30 minute increase & $1.14(1.13$ to 1.14$)$ \\
\hline \multicolumn{2}{|c|}{$\begin{array}{l}\text { COPD }=\text { chronic obstructive pulmonary disease. } \\
{ }^{*} \text { Results from fully adjusted multivariate analysis accounting for all } \\
\text { baseline characteristics. }\end{array}$} \\
\hline
\end{tabular}




\section{WHAT IS ALREADY KNOWN ON THIS TOPIC}

Postoperative pneumonia is a common and serious complication after major surgery in elderly patients

Several randomised trials have reported that gastric acid suppressants sometimes increase the risk of ventilator associated pneumonia in critical care unit patients

\section{WHAT THIS STUDY ADDS}

Patients who received gastric acid suppressants were predisposed to postoperative pneumonia but were also prone to independent risk factors for postoperative pneumonia

Some of the most important risk factors for postoperative pneumonia include a history of chronic obstructive pulmonary disease, heart failure, Parkinson's disease, or pneumonia; nasogastric tubes; and prescriptions of antipsychotics

Accounting for such differences in other risk factors reveals no direct association between gastric acid suppressants and a patient's risk of postoperative pneumonia

cases, and other evidence lacking in administrative databases.

\section{Further limitations}

Negative studies are sometimes prone to biases that differ from those in studies that report significant differences. Over-adjustment bias, for example, sometimes causes adjusted analyses to be less valid than crude analyses. This bias occurs if an event downstream in the course of a disease is mistakenly considered a baseline characteristic. Outcome heterogeneity can be a second potential bias if, for example, acid suppressants were to increase the risk of Gram positive bacterial pneumonia and decrease the risk of Gram negative pneumonia. In such circumstances, a comprehensive analysis might fail to detect either finding. Similarly, patient diversity can be a third bias if the same exposure is helpful to some patients and harmful to other patients, and the patient groups are hard to distinguish. We do not believe these three issues biased our results.

\section{Relative advantages}

One strength of our research relates to its statistical power, with a sample size almost double that of the US National Veterans Affairs Surgical Quality Improvement Program. The design allows the analyses to address the vagaries of ascertaining patient compliance since acid suppressants are not usually changed around elective surgical procedures. ${ }^{44}$ The multicentred sampling provides a rigorous test free of referral bias or selective recruitment. The data also show that postoperative pneumonia diagnostic codes are specific (but not sensitive) given that our crude analysis yielded significant increase in risk similar to recent reports (and a base rate lower than surveillance reports). In addition, the statistical power corroborates other predictors of pneumonia reported in other studies, including use of benzodiazepines and nasogastric tubes.

\section{Clinical relevance}

The implication of our research is that the bacterial colonisation induced by gastric acid suppressants may be a major finding in laboratory experiments but may have little clinical importance for postoperative pneumonia, ${ }^{45-49}$ so that concerns over the safety of acid suppressant therapy in the perioperative setting are perhaps misplaced. Minimising a patient's risk of postoperative pneumonia might be better prioritised through focusing on smoking cessation, optimising nutrition, reducing any psychoactive medications, prompt discontinuation of nasogastric tubes, chest expansion manoeuvres, and other opportunities for protecting the respiratory tract around the time of an operation.

Contributors: We thank Daniel Hackam, David Juurlink, Gabor Kandel, Muhammad Mamdani, Matthew Stanbrook, Damon Scales, Steven Shumak, and Arthur Slutsky for helpful comments on earlier drafts of this article. All authors contributed to the design of the study, interpretation of results, and manuscript preparation. Both DAR and HL were responsible for checking all computer programming and computer output. All authors except $\mathrm{HL}$ were responsible for literature review and bibliography construction. DAR is guarantor and accepts full responsibility for the work, conduct of the study, access to the data, and decision to publish. Funding: This project was supported by the Canada Research Chair in Medical Decision Sciences, a Military Health Services Research grant from the Canadian Forces Health Services, the Physicians Services Incorporated Foundation of Ontario, the Alberta Heritage Foundation fo Medical Research, and the University of Toronto Comprehensive Research Experience for Medical Students programme. The funding organisations had no role in the design and conduct of the study; collection, management, analysis, and interpretation of data; and preparation, review, or approval of the manuscript. The views expressed in this paper are those of the authors and do not necessarily reflect the Ontario Ministry of Health.

Competing interests: All authors have completed the Unified Competing Interest form at www.icmje.org/coi_disclosure.pdf (available on request from DAR) and declare that all authors had: (1) no financial support for the submitted work from anyone other than their employer; (2) no financial relationships with commercial entities that might have an interest in the submitted work; (3) no spouses, partners, or children with relationships with commercial entities that might have an interest in the submitted work; (4) no non-financial interests that may be relevant to the submitted work

Data sharing: No additional data available.

1 Fisher BW, Majumdar SR, McAlister FA. Predicting pulmonary complications after nonthoracic surgery: a systematic review of blinded studies. Am J Med 2002;112:219-25.

2 Qaseem A, Snow V, Fitterman N, Hornbake ER, Lawrence VA, Smetana GW, et al. Risk assessment for and strategies to reduce perioperative pulmonary complications for patients undergoing noncardiothoracic surgery: a guideline from the American College of Physicians. Ann Intern Med 2006;144:575-80.

3 Smetana GW, Lawrence VA, Cornell JE, American College of Physicians. Preoperative pulmonary risk stratification for noncardiothoracic surgery: systematic review for the American College of Physicians. Ann Intern Med 2006;144:581-95.

4 Lawrence VA, Cornell JE, Smetana GW, for the American College of Physicians. Strategies to reduce postoperative pulmonary complications after noncardiothoracic surgery: systematic review for the American College of Physicians. Ann Intern Med 2006;144:596-608.

5 Scarpignato C, Pelosini I, Di Mario F. Acid suppression therapy: where do we go from here? Dig Dis 2006;24:11-46.

6 Mallow S, Rebuck JA, Osler T, Ahern J, Healey MA, Rogers FB. Do proton pump inhibitors increase the incidence of nosocomia pneumonia and related infectious complications when compared with histamine- 2 receptor antagonists in critically ill trauma patients? Curr Surg 2004;61:452-8.

7 Róka R, Rosztóczy A, Izbéki F, Taybani Z, Kiss I, Lonovics J, et al. Prevalence of respiratory symptoms and diseases associated with gastroesophageal reflux disease. Digestion 2005;71:92-6.

8 Driks MR, Craven DE, Celli BR, Manning M, Burke RA, Garvin GM, et al. Nosocomial pneumonia in intubated patients given sucralfate as compared with antacids or histamine type 2 blockers. The role of gastric colonization. N Engl J Med 1987;317:1376-82. 
9 Prod'hom G, Leuenberger P, Koerfer J, Blum A, Chiolero R, Schaller MD, et al. Nosocomial pneumonia in mechanically ventilated patients receiving antacid, ranitidine, or sucralfate as prophylaxis for stress ulcer. A randomized controlled trial. Ann Intern Med 1994;120:653-62.

10 Laheij RJ, Sturkenboom MC, Hassing RJ, Dieleman J, Stricker BH, Jansen JB. Risk of community-acquired pneumonia and use of gastric acid-suppressive drugs. JAMA 2004;292:1955-60.

11 Gulmez SE, Holm A, Frederiksen H, Jensen TG, Pedersen C, Hallas J. Use of proton pump inhibitors and the risk of community-acquired pneumonia: a population-based case-control study. Arch Intern Med 2007;167:950-5.

12 Sarkar M, Hennessy S, Yang YX. Proton-pump inhibitor use and the risk for community-acquired pneumonia. Ann Intern Med 2008;149:391-8.

13 Myles PR, Hubbard RB, McKeever TM, Pogson Z, Smith CJ, Gibson JE. Risk of community-acquired pneumonia and the use of statins, ace inhibitors and gastric acid suppressants: a population-based casecontrol study. Pharmacoepidemiol Drug Saf 2009;18:269-75.

14 Roughead EE, Ramsay EN, Pratt NL, Ryan P, Gilbert AL. Proton-pump inhibitors and the risk of antibiotic use and hospitalisation for pneumonia. Med J Aust 2009;190:114-6.

15 Eurich DT, Sadowski CA, Simpson SH, Marrie TJ, Majumdar SR. Recurrent community-acquired pneumonia in patients starting acidsuppressing drugs. Am J Med 2010;123:47-53.

16 Miano TA, Reichert MG, Houle T,, MacGregor DA, Kincaid EH, Bowton DL. Nosocomial pneumonia risk and stress ulcer prophylaxis: a comparison of pantoprazole vs ranitidine in cardiothoracic surgery patients. Chest 2009;136:440-7.

17 Vakil N. Acid inhibition and infections outside the gastrointestinal tract. Am / Gastroenterol 2009;104(suppl 2):17-20S.

18 [No authors listed.] Do PPIs have long-term side effects? Nexium and the other proton-pump inhibitors are great at reducing stomach acid, but that might have some unintended consequences. Harv Health Lett 2009;34:4-5.

19 Gardner TB, Robertson DJ. Stress ulcer prophylaxis in non-critically il patients: less may be more. Am / Gastroenterol 2006;101:2206-8.

20 Redelmeier DA, Tan SH, Booth GL. The treatment of unrelated disorders in patients with chronic medical diseases. $N$ Engl J Med 1998;338:1516-20.

21 Juurlink DN, Mamdani MM, Lee DS, Kopp A, Austin PC, Laupacis A et al. Rates of hyperkalemia after publication of the Randomized Aldactone Evaluation Study. N Engl I Med 2004;351:543-51.

22 Tu JV, Penfold SP, McColgan, Laupacis A, eds. Access to health services in Ontario: ICES atlas. Institute for Clinical Evaluative Sciences, 2005.

23 American Society of Anesthesiologist Task Force on Preoperative Fasting. Practice guidelines for preoperative fasting and the use of pharmacologic agents to reduce the risk of pulmonary aspiration: application to healthy patients undergoing elective procedures. Anesthesiology 1999;90:896-905.

24 Redelmeier D, Scales D, Kopp A. Beta blockers for elective surgery in elderly patients: population based, retrospective cohort study. $B M$ J 2005;331:932-8.

25 Jackevicius CA, Mamdani M, Tu JV. Adherence with statin therapy in elderly patients with and without acute coronary syndromes. JAMA 2002;288:462-7.

26 Levy AR, O’Brien BJ, Sellors C, Grootendorst P, Willison D. Coding accuracy of administrative drug claims in the Ontario drug benefit database. Can J Clin Pharmacol 2003;10:67-71.

27 Aronsky D, Haug PJ, Lagor C, Dean NC. Accuracy of administrative data for identifying patients with pneumonia. Am J Med Qual 2005;20:319-28.

28 Van de Garde EM, Oosterheert JJ, Bonten M, Kaplan RC, Leufkens HG International classification of diseases codes showed modest sensitivity for detecting community-acquired pneumonia. J Clin Epidemiol 2007;60:834-8.

29 Skull SA, Andrews RM, Byrnes GB, Campbell DA, Nolan TM, Brown GV, et al. ICD-10 codes are a valid tool for identification of pneumonia in hospitalized patients aged $>$ or $=65$ years. Epidemiol Infect 2008;136:232-40.

30 Eber MR, Laxminarayan R, Perencevich EN, Malani A. Clinical and economic outcomes attributable to health care-associated sepsis and pneumonia. Arch Intern Med 2010;170:347-53.

31 Redelmeier DA, Thiruchelvam D, Daneman N. Introducing a methodology for estimating duration of surgery in health services research. J Clin Epidemiol 2008;61:882-9.

32 Daneman N, Simor AE, Redelmeier DA. Validation of a modified version of the national nosocomial infections surveillance system risk index for health services research. Infect Control Hosp Epidemiol 2009;30:563-9.

33 Arozullah AM, Khuri SF, Henderson WG, Daley J, for the Participants in the National Veterans Affairs Surgical Quality Improvement Program. Development and validation of a multifactorial risk index for predicting postoperative pneumonia after major noncardiac surgery. Ann Intern Med 2001;135:847-57.

34 McAlister FA, Bertsch K, Man J, Bradley J, Jacka M. Incidence of and risk factors for pulmonary complications after non-thoracic surgery. Am I Resp Crit Care Med 2005;171:514-7.

35 Goel V, Williams J, Anderson G, Blackstien-Hirsch P, Fooks C, Naylor D. Patterns of health care in Ontario. 2nd ed. Institute for Clinical Evaluative Sciences, 1996.

36 Redelmeier DA, Thiruchelvam D, Daneman N. Delirium after elective surgery among elderly patients taking statins. CMAJ 2008;179:645-52.

37 Froehner M, Koch R, Litz R, Heller A, Oehlschlaeger S, Wirth MP. Comparison of the American Society of Anesthesiologists' physical status classification with the Charlson score as predictors of survival after radical prostatectomy. Urology 2003;62:698-701.

38 Goel V, Naylor D, Anderson G. Patterns of health care in Ontario. 1st ed. Institute for Clinical Evaluative Sciences, 1994.

39 Bajaj JS, Zadvornova Y, Heuman DM, Hafeezullah M, Hoffmann RG, Sanyal AJ, et al. Association of proton pump inhibitor therapy with spontaneous bacterial peritonitis in cirrhotic patients with ascites. Am J Gastroenterol 2009;104:1130.

40 Eurich DT, Sadowski CA, Simpson SH, Marrie TJ, Majumdar SR. Recurrent community acquired pneumonia in patients starting acid suppressing drugs. Am J Med 2010;123:47-53.

41 Herzig SJ, Howell MD, Ngo LH, Marcantonio ER. Acid suppressive medication use and the risk of hospital acquired pneumonia. JAMA 2009;301:2120-8

42 Horwitz RI, Feinstein AR. The problem of "protopathic bias" in casecontrol studies. Am / Med 1980;68:255-8.

43 Smetana GW, Lawrence VA, Cornell JE, for the American College of Physicians. Preoperative pulmonary risk stratification for noncardiothoracic surgery: systematic review for the American College of Physicians. Ann Intern Med 2006;144:581-95.

44 Bell CM, Bajcar J, Bierman AS, Li P, Mamdani MM, Urbach DR. Potentially unintended discontinuation of long-term medication use after elective surgical procedures. Arch Intern Med 2006;166:2525-31.

45 Du Moulin GC, Paterson DG, Hedley-White J, Lisbon A. Aspiration of gastric bacteria in antacid-treated patients: a frequent cause of postoperative colonization of the airway. Lancet 1982;1:242-5.

46 Stockbruegger RW. Bacterial overgrowth as a consequence of reduced gastric acidity. Scand J Gastroenterol 1985;111:7-16.

47 Hartmann M, Theiss U, Huber R, Lühmann R, Bliesath H, Wurst W, et al. Twenty-four-hour intragastric $\mathrm{pH}$ profiles and pharmacokinetics following single and repeated oral administration of the proton pump inhibitor pantoprazole in comparison to omeprazole. Aliment Pharmacol Ther 1996;10:359-66.

48 Williams C, McColl KE. Review article: proton pump inhibitors and bacterial overgrowth. Aliment Pharmacol Ther 2006;23:3-10.

49 Kirchheiner J, Glatt S, Fuhr U, Klotz U, Meineke I, Seufferlein T, et al. Relative potency of proton-pump inhibitors-comparison of effects on intragastric pH. Eur J Clin Pharmacol 2009;65:19-31.

Accepted: 25 March 2010 